\title{
Conjunctival squamous cell carcinoma in Tanzania
}

\author{
T R G Poole
}

\begin{abstract}
Aims-To assess changes in incidence of conjunctival squamous cell carcinoma over a 22 year period in Tanzania and to analyse possible reasons for change.

Methods-Retrospective analysis of records from a Tanzanian pathology department serving north and central Tanzania from 1976 to 1997; medical record analysis of cases of conjunctival squamous cell carcinoma presenting in the last 2 years of the study.

Results-There was a sharp rise in the incidence of conjunctival squamous cell carcinoma in the last 3 years of the study (1995-7). The mean age of patients presenting with the condition over the full period was 44.7 years (95\% confidence interval 42.4-46.9 years). In the final 2 years of the study the mean length of history on presentation was 3.1 months (2.14.0 months). Several patients had a previous history of chronic conjunctival disease such as allergic conjunctivitis and trachoma; one had had a conjunctival papilloma excised previously. Only five patients had been tested for HIV status, but of these four were positive.

Conclusion-Tanzania is experiencing an epidemic of conjunctival squamous cell carcinoma similar to that seen in other African countries. Often the tumours are aggressive and occur in patients of relatively young age. The epidemic appears to be related to HIV infection, on a background of ultraviolet light exposure. Previous chronic conjunctival disease and exposure to human papillomavirus may also have a role.
\end{abstract}

(Br F Ophthalmol 1999;83:177-179)

In recent years an increasing incidence of conjunctival squamous cell carcinoma has been noted in Rwanda, ${ }^{1}$ Uganda, ${ }^{2}$ and Malawi, ${ }^{3}$ with a strong association with HIV infection. Ultraviolet light has previously been implicated as the major risk factor for these tumours, ${ }^{4}$ which have been more common in equatorial Africa than Europe or North America. The added importance of HIV infection is now becoming clear. Recently the role of human papillomavirus (HPV) as a cofactor has been studied, because of its relation with anal and cervical carcinomas in patients with HIV infection. In one study, HPV-16 was strongly associated with conjunctival squamous cell carcinoma. $^{5}$

At the Kilimanjaro Christian Medical Centre in Northern Tanzania, a similar increase in young patients presenting with conjunctival tumours to the ophthalmic outpatient clinic seemed apparent. This was investigated by studying the pathological records, and the medical records of the most recent cases, including identification of possible risk factors.

\section{Subjects and methods}

Kilimanjaro Christian Medical Centre (KCMC), one of the largest hospitals in Tanzania, is a referral hospital serving five regions in northern and central Tanzania: Kilimanjaro, Arusha, Singida, Tanga, and Dodoma (population approximately 8 million).The pathology department processes histological specimens from KCMC, but also receives specimens from other hospitals and smaller village health centres in northern and central Tanzania. Records at the KCMC pathology department were reviewed for cases of conjunctival squamous cell carcinoma since full records began in 1976. In the years 1989-93 there was no pathologist at the hospital and records in these years are absent. In all positive cases the patient's age, sex, and any other relevant details were noted. For the years 1996 and 1997 the results of all conjunctival biopsies were noted. In addition, all cases of squamous cell carcinoma in these 2 years who had medical records at KCMC had their hospital number noted. Their notes were then reviewed for further details such as length of history and any previous ophthalmic history.

\section{Results}

In total, 215 cases of conjunctival squamous cell carcinoma were diagnosed from 1976 to 1988 and from 1994 to 1997 . In four cases the sex had not been documented. Of the remaining 211,109 were male $(51.7 \%)$. From 1976 to 1988 there were 108 cases, an average of 8.3 per year. In 1994 there were 10 cases; in 1995, 20 cases; in 1996, 37 cases; and in 1997, 40 cases (Fig 1). The mean age from 1976 to 1997 was 44.7 years (95\% confidence interval $42.4-$ 46.9 years). The change in mean age from year to year did not show any significant trend. Seven patients were children with xeroderma pigmentosa, an autosomal recessive condition more commonly seen in Africa than Europe, characterised by an impaired ability to repair sunlight damaged DNA, and therefore a propensity to ultraviolet associated tumours, including conjunctival tumours. They were excluded from any calculations of mean age so as not to affect the mean age of the majority of cases unassociated with the condition.

To assess whether these results showed a true increase, rather than a reflection of increased consultations at KCMC, outpatient 


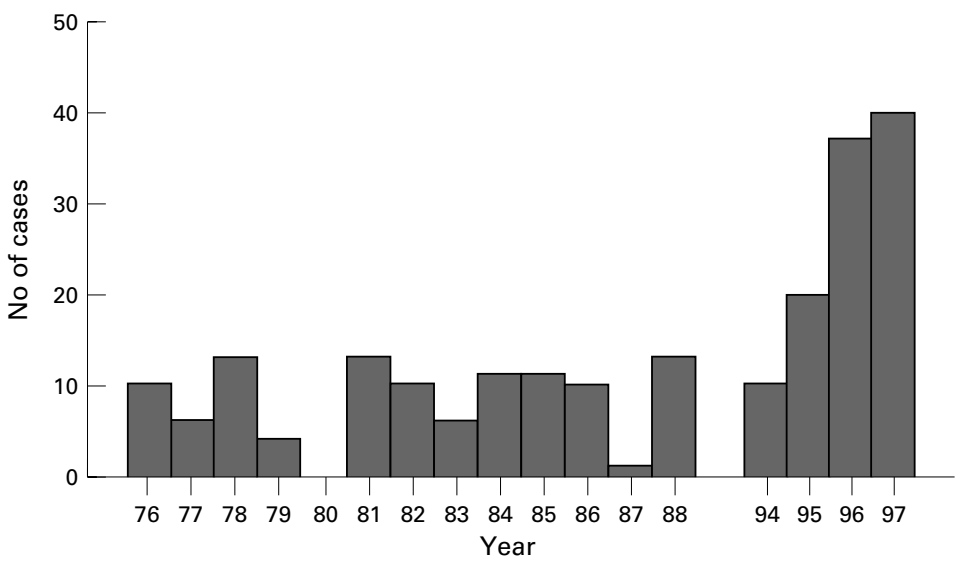

Figure 1 Cases of conjunctival squamous cell carcinoma per year.

Table 1 Results of conjunctival biopsies in 1996 and 1997

\begin{tabular}{lccc}
\hline Histology & 1996 & 1997 & Total \\
\hline Squamous cell carcinoma & 37 & 40 & 77 \\
Pingueculum/pterygium & 22 & 13 & 35 \\
Actinic keratosis & 16 & 8 & 24 \\
"Chronic inflammation" & 3 & 4 & 7 \\
Papilloma & 2 & 4 & 6 \\
Naevus & 1 & 3 & 4 \\
"Pyogenic granuloma" & 2 & 2 & 4 \\
Dysplasia & 1 & 2 & 3 \\
Kaposi's sarcoma & - & 2 & 2 \\
Haemangioma & - & 3 & 3 \\
Lymphoma & - & 2 & 2 \\
Conjunctival cyst & - & 1 & 1 \\
\end{tabular}

and theatre records were studied. Records available from 1989 to 1997 did not show any trend of increasing workload to correspond with the rise in conjunctival pathology seen. Specifically, in the years of most change, 1994-7, total outpatients seen in the year remain steady at the 13000 level (maximum 13827 in 1996, minimum 13013 in 1997). Total operations showed a decrease from 1994 (1985 operations) to 1997 (1188 operations). The figures seen above are therefore likely to show a true increase in conjunctival squamous cell carcinoma.

In 1996 and 1997 a total of 168 conjunctival biopsies were analysed. Of these 77 were squamous cell carcinomas (45.8\%). Most others were pingueculae or pterygia, or actinic keratosis, although other malignant conditions were seen such as Kaposi's sarcoma and

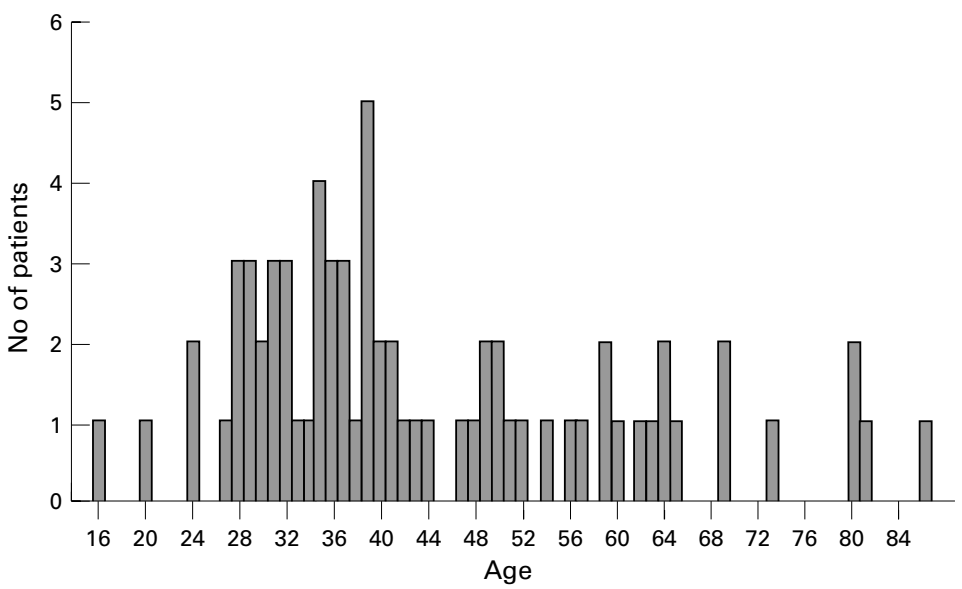

Figure 2 Age of patients with conjunctival squamous cell carcinoma in 1996 and 1997. lymphoma. Full biopsy details are shown in Table 1.

The 77 patients with squamous cell carcinoma from January 1996 to December 1997 had a mean age of 45.3 years $(95 \%$ confidence interval 41.4-49.2 years; median age 39.0 years; range 16-86 years; one 5 year old boy with xeroderma pigmentosa excluded from calculation). The spread of their ages is shown in Figure 2. There were 38 males (including xeroderma pigmentosa case), 37 females, and two patients whose sex had not been documented. Of these 77 patients, 34 had had medical records at KCMC. Of these 31 were available for review. The mean length of history of a conjunctival abnormality on questioning at first presentation was 3.1 months (95\% CI 2.1-4.0 months).

Because of problems financing testing for HIV seropositivity, and availability of testing reagents, only five of the 31 patients with notes available for review had had HIV testing by ELISA confirmed by western blot. Of these five, four were positive. Four patients had had previous conjunctival biopsies from the same eye. Their results had been two pterygia, one conjunctival dysplasia, and one papilloma. Two patients had a previous history of trachoma, and four patients had had chronic allergic conjunctivitis several years before, and had been treated with topical steroid drops.

\section{Discussion}

The epidemic of conjunctival squamous cell carcinoma is now being seen in Tanzania. This would seem from previous evidence to be linked to the HIV epidemic ${ }^{1-3}$; this study is only suggestive of that link, with four of only five cases tested proving seropositive for HIV. With this probable association with the HIV epidemic, one might have expected to see more cases of Kaposi's sarcoma of the conjunctiva, but only two cases were seen in 1997. The reasons for this are not clear. It is interesting that the increasing incidence has been seen 6 years later than the beginning of the increase in conjunctival squamous cell carcinoma in Uganda, which appeared to start in $1989 .^{2}$ This may be due to differing patterns of the HIV epidemic in east Africa. We do know that few countries in sub-Saharan Africa have reliable data on HIV infection, but that the epidemic is far worse than previously thought in 1996, particularly in sub-Saharan Africa, where there are now an estimated 20.8 million people infected with HIV. ${ }^{6}$ The tumours seen in Tanzania certainly appear to be mostly occurring in a relatively young age group, and appear to be quite aggressive, with rapid growth over a short time. What is also interesting is the fact that the mean age of these patients has not changed significantly in 22 years. It may be that even in 1976 HIV infection was playing a role in the aetiology of conjunctival squamous cell carcinoma. Unfortunately there are no data available on prevalence of conjunctival tumours in east Africa.

Other processes may also be important in the aetiology of conjunctival squamous cell 
carcinoma. Ultraviolet flux at the earth's surface is strongest at low latitudes and high altitudes; northern Tanzania is less than 400 kilometres from the equator and at altitude (KCMC is at approximately 900 metres). Ozone depletion may be increasing the already high ultraviolet levels. It has been estimated that for every $1 \%$ decline in the ozone layer there will be a $2-3 \%$ increase in the incidence of non-melanoma skin cancer, ${ }^{7}$ and this increase would be expected to apply to conjunctival squamous cell carcinoma. Information on ozone levels over Africa is very sparse, but local sources indicate the possibility of an ozone hole in the Kilimanjaro area (personal communication, Dar es Salaam: Tanzanian Ministry of Health). This may be another contributing factor to the changing incidence of conjunctival carcinoma.

Human papillomavirus has also been implicated in conjunctival squamous cell carcinoma, ${ }^{5}$ and one patient in 1997 had had a histologically confirmed squamous papilloma excised previously before developing a squamous carcinoma. Three other patients had had previous conjunctival lesions biopsied (two pterygia, one dysplasia) and six more had a previous history of chronic conjunctival disease (four chronic allergic conjunctivitis, two trachoma). These patients may indicate the importance of previous chronic conjunctival disease in the pathogenesis of conjunctival carcinoma. It may be that HIV infection has a permissive effect on cellular changes brought about by ultraviolet light and previous conjunctival disease that would normally be corrected by a properly functioning immune system.

I thank the Pathology Department at KCMC. This study has been supported by grants from the British Council for the Prevention of Blindness and the Ulverscroft Foundation.

1 Kestelyn P, Stevens AM, Ndayambaje A, et al. HIV and conjunctival malignancies. Lancet 1990; 336:51-2.

2 Ateenyi-Agaba C. Conjunctival squamous cell carcinoma associated with HIV infection in Kampala, Uganda. Lancet 1995;345:695-6.

3 Waddel KM, Lewallen S, Lucas SB, et al. Carcinoma of the conjunctiva and HIV infection in Uganda and Malawi. Brf Ophthalmol 1996;80:503-8.

4 Lee GA, Hirst LW. Ocular surface squamous neoplasia. Surv Ophthalmol 1995;39:429-50.

5 McDonnell JM, McDonnell PJ, Sun YY. Human papilloma DNA in tissue and ocular surface swabs of patients with conjunctival epithelial neoplasia. Inv Ophthalmol Vis Sci 1992;33:184-9.

6 Wise J. HIV epidemic is far worse than thought. BMF 1997; 315:1486 (news).

7 Beadle PC, Leach JF. Holidays, ozone and skin cancer. Arch Dermatol Res 1982;274:47-56. 